\title{
Study on the Change in Powder Properties of Rice Flour by Different Milling
}

\section{Processes}

(Received November 5, 2016; Accepted October 5, 2017)

(J-STAGE Advance Published Date: October 27, 2017)

\author{
Daitaro Ishikawa, ${ }^{1, \dagger}$ Ikumi Sawa, ${ }^{1}$ Yasuyo Sekiyama, ${ }^{2}$ Akemi K. Horigane, ${ }^{2}$ Tomoya Okunishi, ${ }^{2}$ Keiko Fujii, ${ }^{3}$ \\ and Tomoyuki Fujii ${ }^{1}$ \\ ${ }^{1}$ Graduate school of Agricultural Science, Tohoku University \\ (468-1 Aoba Aramaki, Aoba-ku, Sendai, Miyagi 981-8555, Japan) \\ ${ }^{2}$ NARO Food Research Institute \\ (2-1-12 Kan-nondai, Tsukuba, Ibaraki 305-0856, Japan) \\ ${ }^{3}$ Faculty of Human Sciences and Design, Japan Women's University \\ (2-8-1 Mejirodai, Bunkyo-ku, Tokyo 112-8681, Japan)
}

\begin{abstract}
The aim of this study was to clarify the change in the powder properties of rice flour depending on the milling process. Rice flour samples, which have gradual mechanical shock properties, were prepared using different milling methods. Furthermore, the correlation between the starch damage, owing to mechanical shock, and powder properties of rice flour was investigated. The particle size was changed gradually through each milling process; however, the change did not clearly correlate with starch damage. The results of the X-ray diffraction (XRD) pattern of nongelatinized samples showed the typical A-type structure of starch. The crystal structure of starch in rice flour may change to a disorder state with the progress of milling; thus, in this study, instead of crystallinity, we considered the disorder index (DI) calculated from the XRD intensity of samples. Relationship between DI and starch damage was confirmed with $R^{2}=0.923$. Therefore, the mechanical shock caused by the milling process contributes to the crystal state of starch. The parameter $q_{\mathrm{m}}$ calculated from the GuggenheimAnderson-de Boer (GAB) equation of each sample corresponded to the DI. This result suggested that the sorption site of rice flour decreased, and a positive correlation was observed between the parameter $K$ and DI. Thus, the interaction between the rice flour and water molecules weakened because of the mechanical shock. In addition, the use of a SEM image supports the insight that the change in parameter $K$ may reflect the structural change in the solid phase. These results demonstrated that the change in powder properties of rice flour caused by mechanical shock of the milling could evaluate quantitatively.
\end{abstract}

Key words: disorder index, GAB parameters, milling process, starch damage, X-ray diffraction

\section{INTRODUCTION}

Rice flour is important for the research and development of new food products. To increase the food self-sufficiency ratio in Japan, improvement in the applications of rice flour seems essential. In the past decades, rice flour has been widely used as a substitute of other flours in the preparation of breads, sweets, and noodles.

Starch is the main component in most common types of cereal products such as rice flour, and a number of studies have reported on its fundamental properties, such as crystallinity, granularity, and spatial structure. ${ }^{12) 334) 566)}$ Moreover, X-ray diffraction (XRD) and nuclear magnetic resonance (NMR) spectra, combined with molecular simulation, have provided detailed information on the high order structure of starch; consequently, progress in the characterization of starch as a biomaterial has been remarkable.7)

${ }^{\dagger}$ Corresponding author (Tel. +81-22-757-4410,

E-mail: daitaroishikawa@m.tohoku.ac.jp).
Additionally, previous studies have showed that mechanical treatment led the alteration of starch crystallinity and internal structures. ${ }^{8) 910) 11) 12) 13) 14) ~ F o r ~ i n s t a n c e, ~ b a l l ~ m i l l i n g ~ i s ~}$ known as an effective method for converting the semicrystalline state of starch into an amorphous state, resulting in gradual changes in its molecular structure, crystalline structure, and water solubility. ${ }^{15)}$ Starch damage is used as an effective evaluation index for the biochemical degradative state because it is not constrained by the conversion from cereal to flour. ${ }^{16) 17) 18)}$ Morrison and Tester reported the correlation between crystallinity and molecular order of starch, and the starch damage caused by ball milling. ${ }^{1920) 21 \text { ) }}$

On a more practical scale, several studies have investigated the powder properties and bulk characteristics of flours used in food products, especially in breads. ${ }^{22) 23) 24)}$ Water sorption capacity is improved by the presence of damaged starch granules, which contribute to the development of a desirable dough texture. ${ }^{13)}$ Our research group has also demonstrated the production potential of rice flour with controlled moisture sorption. ${ }^{25) 26)}$ 
Table 1. Summary of milling methods, Rotation speed and diameter of screen hole for rice flours.

\begin{tabular}{|c|c|c|c|c|c|}
\hline Sample & Milling methods & Machine type & $\begin{array}{l}\text { Rotation speed } \\
\quad(\mathrm{rpm})\end{array}$ & $\begin{array}{l}\text { Screen hole's } \\
\text { diameters } \\
(\mathrm{mm})\end{array}$ & $\begin{array}{c}\text { Other } \\
\text { conditions }\end{array}$ \\
\hline $\mathrm{RFa}$ & Pin mill $\rightarrow$ Pin mill & DD-2 $\rightarrow$ DD-2 & 3,600 & $\varphi 3.0 \rightarrow \varphi 0.3$ & - \\
\hline $\mathrm{RFb}$ & Pulverizing mill & EM-2 & 10,000 & - & - \\
\hline $\mathrm{RFc}$ & Pin mill $\rightarrow$ Pulverizing mill & DD-2 $\rightarrow$ EM-2 & $3,600 \rightarrow 10,000$ & $\varphi 3.0 \rightarrow-$ & - \\
\hline RFd & Pin mill $\rightarrow$ Pulverizing mill & DD-2 $\rightarrow$ EM-2 & $3,600 \rightarrow 10,000$ & $\varphi 3.0 \rightarrow-$ & Add $5 \%$ water \\
\hline $\mathrm{RFe}$ & Gelatinized mill & HSM-250 & - & - & Heated $130{ }^{\circ} \mathrm{C}$ \\
\hline
\end{tabular}

More recently, Tran et al. have stated that the particle size, starch damage, and starch molecular structure of rice flour could be altered by varying the temperature, time, and types of milling. ${ }^{27)}$ On the other hand, Anzai et al. have reported that enthalpy relaxation was promoted through mechanical shock during the ball milling process, which contributes to the formation of an amorphous structure in rice flour. ${ }^{28)}$ Nevertheless, the alteration of the sorption property and high order structure caused by mechanical shock have not fully been investigated. ${ }^{29)}$

The aim of the current study is to evaluate the powder properties of rice flour altered through the milling process. Especially, it is very important to note that the expected polymer structure may be generated as a disordered structure owing to the mechanical shock caused by milling. ${ }^{30}$ Therefore, in this study, rice flour samples with different starch states were prepared using the designed milling process. Additionally, powder properties corresponding to the particle and molecule scales were investigated from the viewpoint of the polymer order-disordered process.

\section{MATERIALS AND METHODS}

Sample preparation-based starch damage. White rice, c.v. Hitomebore, harvested in 2015 at Miyagi Prefecture, Japan was used for preparation of the flour. Five types of rice flour samples (RFa, b, c, d, and e) were gradually prepared by controlling the screen diameter and rotation of the mill, as presented in Table 1 . The initial water contents of RFa-e were $0.125,0.118,0.117,0.167$, and 0.053 [g-water/g-d.s.], respectively. RFa was produced by milling the rice twice in a pin mill (Makino's impact universal pulverizer; DD-2, Makino mfg. Co. Ltd., Tokyo, Japan). Initially, the rice was milled using a $3.0 \mathrm{~mm}$ diameter screen hole, followed by milling using a $0.3 \mathrm{~mm}$ diameter screen hole at 3,600 rpm. Additionally, $\mathrm{RFb}$ was prepared in a pulverized mill at 10,000 rpm by using an exceed mill (EM-2, Makino mfg. Co. Ltd., Tokyo, Japan). To produce RFc and RFd, pin milling was first conducted at 3,600 rpm by using the DD-2 pin mill, and then these samples were subjected to pulverized milling at 10,000 rpm by using EM-2. The screen-hole diameter for preparation of RFc and RFd was $3.0 \mathrm{~mm}$. Note that in the case of RFd, $5 \%$ water per wet weight was added to the first-milled rice flour before the second milling process by using EM-2. For RFe, gelatinized rice flour was produced using a heat and shear milling machine (HSM-250, Seishin Enterprise Co. Ltd., Tokyo, Japan) according to the novel method developed by Katsuno et al.
${ }^{31)}$ This machine can simultaneously provide mechanical shear and heat to a sample during milling without the addition of water. In this study, the white rice was subjected to mechanical shear at $130^{\circ} \mathrm{C}$ in this machine.

Determination of starch damage. The starch damage of each sample was determined using the starch damage assay kit (Megazyme International Ireland, Ltd, Bray, Ireland). $\alpha$ Amylase $(1 \mathrm{~mL} ; 50 \mathrm{U} / \mathrm{mL})$ was added to $100 \mathrm{mg}$ rice flour and the solution was decomposed at $40{ }^{\circ} \mathrm{C}$ for $10 \mathrm{~min}$. The decomposed solution was centrifuged at 3,000 rpm for 5 min. Amyloglucosidase $(0.1 \mathrm{~mL} ; 2 \mathrm{U} / \mathrm{mL})$ was added to the supernatant, and the solution was decomposed at $40{ }^{\circ} \mathrm{C}$ for $20 \mathrm{~min}$. Finally, the absorbance of this solution was measured at $510 \mathrm{~nm}$ and the starch damage of each sample was assessed.

X-ray diffraction. X-ray diffraction (XRD) patterns of each sample were recorded using a diffractometer (X'pert MPD, PHILIPS Japan Ltd., Tokyo, Japan) with the $2 \theta$ range of $5^{\circ}-30^{\circ}$ and $\mathrm{CuK}_{\alpha 1}$ radiation $\left(\lambda=1.5405^{\circ}\right)$.

\section{Sorption property.}

1. Calculation of $\boldsymbol{G A B}$ parameters . Nine desiccators with 11.0, 22.4, 33.0, 47.0, 55.7, 70.8, 80.7, 90.1, and 98.0\% relative humidity were prepared using saturated solutions of $\mathrm{LiCl}, \mathrm{CH}_{3} \mathrm{COOK}, \mathrm{MgCl}_{2}, \mathrm{LiNO}_{3}, \mathrm{NaBr}, \mathrm{SrCl}_{2}, \mathrm{KI}$, $\mathrm{BaCl}_{2}$, and $\mathrm{K}_{2} \mathrm{Cr}_{2} \mathrm{O}_{7}$, respectively.

The rice flours were kept in each desiccator at $25{ }^{\circ} \mathrm{C}$ until equilibration of water sorption was achieved, and each sample was dried at $105{ }^{\circ} \mathrm{C}$ for three days. As described by Anzai et al., the initial water content under ambient conditions was precisely measured and referred to as the dry state. ${ }^{28)}$ Furthermore, these samples were reweighed and their moisture contents, represented by $q$ [g-water/g-d.s.], were calculated.

The Guggenheim-Anderson-de Boer (GAB) equation was fitted to the obtained water sorption isotherm for each sample, and the GAB parameters of $q_{\mathrm{m}}, c$, and $K$ were determined through the following equation:

$$
q=\frac{q m c K a_{w}}{\left(1-K a_{w}\right)\left(1-K a_{w}+c K a_{w}\right)}
$$

where $a_{\mathrm{w}}$ is the water activity of material, $q_{\mathrm{m}}$ is the partition function of molecule in multilayer, $c$ is the Guggenheim constant in the GAB sorption equation, and $K$ is the constant in the GAB sorption equation factor corresponding to properties of the multilayer molecules relative to the bulk liquid.

2. Scanning election microscopy. The change of sample surface due to deferent humidity was investigated by scan- 
Table 2. Summary of distribution parameters and starch damage of samples.

\begin{tabular}{cccccc}
\hline & $\mathrm{RFa}$ & $\mathrm{RFb}$ & $\mathrm{RFc}$ & $\mathrm{RFd}$ & $\mathrm{RFe}$ \\
\hline Distribution parameters & & & & & \\
Mean $(\mu \mathrm{m})$ & 385 & 133 & 120 & 196 & 230 \\
Mode $(\mu \mathrm{m})$ & 399 & 126 & 100 & 159 & 126 \\
2nd peak & - & - & - & - & 893 \\
Kurtosis & 2.77 & 2.36 & 2.02 & -0.63 & \\
Skewness & 2.02 & 1.90 & 1.80 & 0.92 & \\
Starch damage $(\%)$ & 4.1 & 10.0 & 13.0 & 9.9 & 79.8 \\
\hline
\end{tabular}

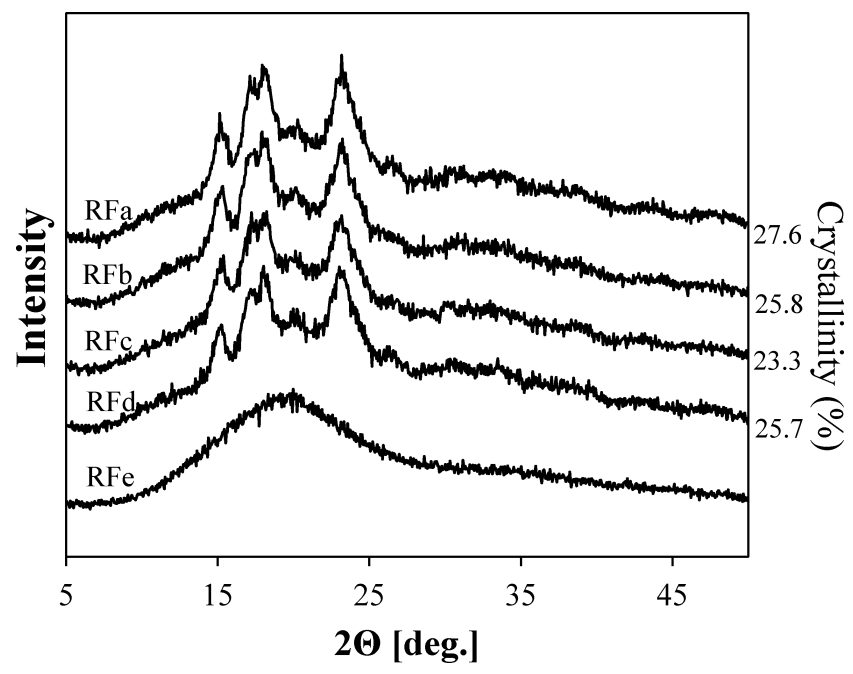

Fig. 1. XRD pattern of each sample Note that the numbers at the right side indicate crystallinity (\%) of the samples.

ning electron microscope (Quanta 200, FEI. Co., Japan Ltd., Tokyo, Japan). This microscope can acquire an image under different humidity conditions via the environmental scanning electron microscopy mode.

\section{RESULTS AND DISCUSSION}

\section{Change in particle size and crystallinity caused by me- chanical shock.}

Table 2 summarizes the distribution parameters of starch particles and starch damage in the samples. The modes of particle sizes of RFa-RFe were 399, 126, 100, 159, and 126 $\mu \mathrm{m}$. These values did not correlate with the starch damage. In the case of RFe, a small peak appeared at $893 \mu \mathrm{m}$; however, this peak did not require an interpretation in this study. The kurtosis and skewness of RFa were the highest among the rice flours, and those of RFd were approximately zero. This result suggests that the milling methods used in this study could produce rice flours with varied particle sizes.

Figure 1 shows the XRD pattern of each sample. An amorphous trend was observed for RFe. In the other four types of rice flours, the peaks were observed approximately at $2 \theta=15^{\circ}, 18^{\circ}, 19^{\circ}$, and $24^{\circ}$. These peaks were typically of the A type, indicating the crystalline structure of ordinary rice starch. ${ }^{1)}$ A small peak of $2 \theta=21^{\circ}$ was observed, possibly because of the ordered single amylose. ${ }^{7)}$

To understand the physicochemical properties of a poly-
Table 3. Summary of correction coefficient $\alpha$ for calculation of disorder index (DI), Eq. (2).

\begin{tabular}{lc}
\hline & $\alpha$ \\
\hline $\mathrm{RFa}$ & 1.42 \\
$\mathrm{RFb}$ & 1.36 \\
$\mathrm{RFc}$ & 1.29 \\
$\mathrm{RFd}$ & 1.37 \\
\hline
\end{tabular}

mer, the investigation of its crystallinity is generally performed using the XRD patterns. ${ }^{32)}$ However, the quantitative method for starch crystallinity is not completely established because the preparation of a $100 \%$ crystalline sample is difficult. ${ }^{33)}$ Moreover, as mentioned earlier, the structure of rice flour may change to a disordered structure because of mechanical shock. Therefore, the investigation of the disorder level in the polymer structure is intrinsic to understanding the change in powder properties of starch owing to milling. Therefore, we experimentally calculated the disorder index (DI) from the intensity ratio of RFe and the other rice flours as follows:

$$
\mathrm{DI}=I_{\text {amor }} / \alpha I_{\text {total }}
$$

where $I_{\text {amor }}$ is the integrated intensity in the $14^{\circ}-25^{\circ}$ region of RFe, and $I_{\text {total }}$ is the integrated intensity in the $14^{\circ}$ $25^{\circ}$ region of all the other flours. In this study, the intensity of $\mathrm{RFa}-\mathrm{RFd}$ in the $14^{\circ}-25^{\circ}$ region was adjusted by the coefficient $\alpha$ as packing fraction (presented in Table 3 ). $\alpha$ was determined in such manner that the intensity of bottom peaks of $\mathrm{RFa}-\mathrm{RFd}$ in the $14^{\circ}-25^{\circ}$ region corresponded to the intensity of RFe.

Figure 2 shows the double logarithmic plot of the starch damage to DI. It was possible to fit the data with the power law $\left(R^{2}=0.923\right)$. The starch granules and crystallinity of the rice flour gradually changed because of the mechanical shock of different milling types. Thus, as Lelievre reported, ${ }^{16)}$ this result demonstrates that the damaged part of the starch in rice flour was slightly converted to amorphous. Interestingly, when the DI was $1(\log$ DI $=0)$, starch damage was indicated as $79.8 \%$ (Table 1); that is, RFe used as the gelatinized sample still comprised the ordered region. When starch damage was $80 \%$ during the ball milling process of wheat starch, the crystallinity was indicated as $8.5 \%{ }^{19)}$ With a similar physical modification technique, Katsuno et al. pointed out that the ball-mill treatment is an effective method for obtaining amorphous starch without adding water. $^{31)}$ Recently, Anzai et al. reported that rice flour was almost completely amorphous after ball-milling. ${ }^{34)}$ In addition, gelatinization was generated by increasing temperature in a mill machine during the milling process. In fact, Katsuno et al. reported that amorphous starch could be produced at $80{ }^{\circ} \mathrm{C}$ or higher temperature. ${ }^{31)}$ Because in this study, the temperature of each sample was around $40-50{ }^{\circ} \mathrm{C}$ after milling, the gelatinization caused by the heat of milling was not considered. However, to alter the residual ordered region, the milling method must be optimized in the future with respect to time and temperature.

The DIs of RFa-RFd were 72.4, 74.2, 76.6, and 74.3, respectively. Although the milling process for RFc and RFd 


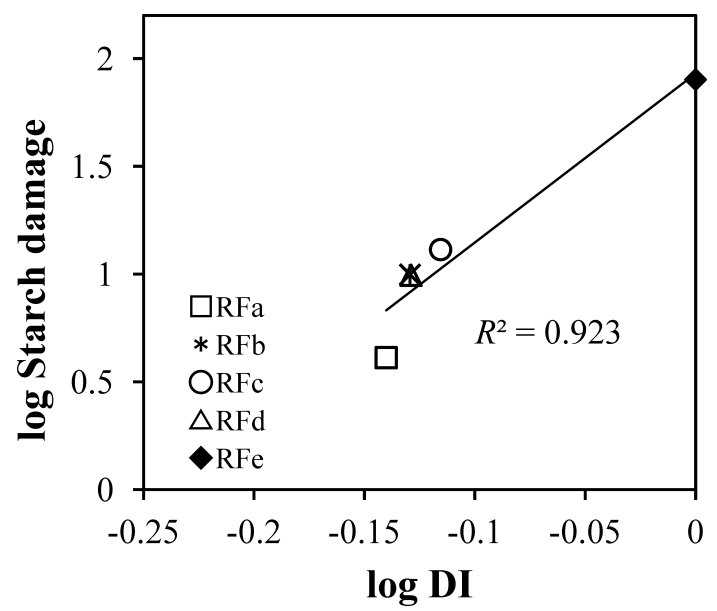

Fig. 2. Relationship between the disorder index (DI) calculated from Eq.(2) and starch damage of each sample.

was almost identical, except for the addition of water (Table 1), the DI of RFd was lower than that of RFc. Thus, it is very likely that RFc was strongly affected by the frictional heat at the surface compared to RFd, and the starch in its rice flour was more severely damaged.

Change in sorption properties by mechanical shock.

Figure 3 depicts the moisture sorption isotherm of each sample. A sigmoidal behavior was confirmed in all samples. In the low and high $a_{\mathrm{w}}$ regions, a rapid increase in moisture content can be observed with convexity and concavity of the curve, and a constant increase can be seen between $a_{\mathrm{w}}$ and the moisture contents in the middle region of $a_{\mathrm{w}}$. As numerous studies have shown, this is a typical type II isotherm. ${ }^{23)}$

These behaviors are consistent with the GAB equation defined in Eq. (1). The fitting potential of the GAB equation was discussed in a previous study. ${ }^{35)}$ Particularly, the study noted that the accuracy in the high $a_{\mathrm{w}}$ region was relatively lower than that in the $0.076-0.90$ region. ${ }^{35)}$ However the results predicted in $0.076-0.90$ and $0.0-0.98 a_{\mathrm{w}}$ regions were almost identical in this study. Consequently, the fitting in the $0.0-0.98 a_{\mathrm{w}}$ region was used in the analysis.

Figure 4 illustrates the relationship between the GAB parameters of each sample and the DI. The parameter $q_{\mathrm{m}}$ of $\mathrm{RFa}-\mathrm{RFd}$ was obtained as $0.071 \pm 0.001,0.068 \pm 0.001$, $0.061 \pm 0.000$, and $0.071 \pm 0.002$, respectively. The figure demonstrates a negative correlation between $q_{\mathrm{m}}$ and DI.

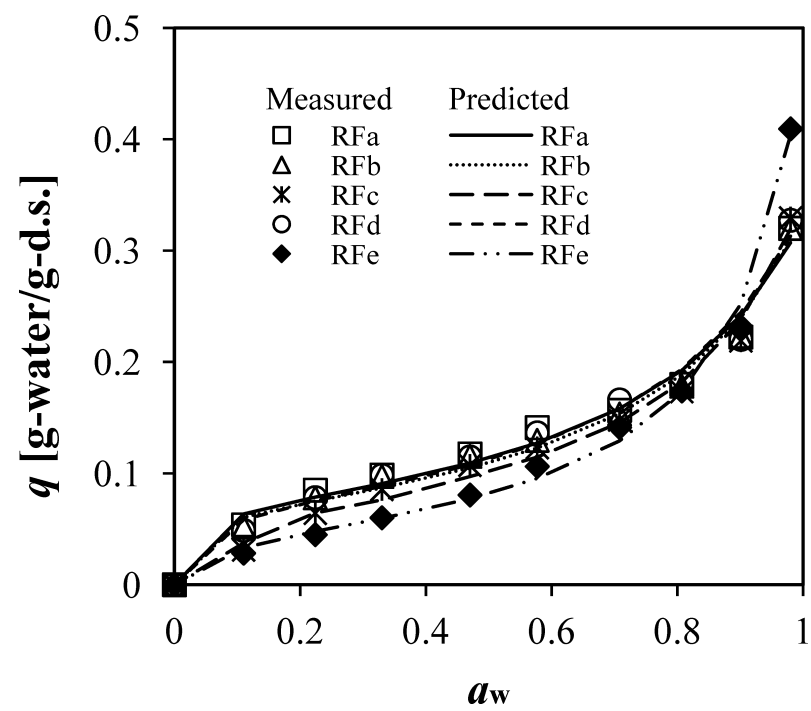

Fig. 3. Moisture sorption isotherm for starch flour samples.

This result suggests that the number of sorption sites of rice flour subjected to severe mechanical shock decreased compared with that in the case of low mechanical shock.

The sorption mechanism of starch has been reported by many researchers because its structure is complicated as well as inhomogeneous. ${ }^{32)}$ Although the discussion about the sorption position is still under development, the results obtained in the present study may provide additional assumptions about the water sorption system of rice flour. Particularly, it is conceivable that the sorption sites exist not only on the surface of rice flour but also on its internal structure, and certain water molecules were sorbed specifically at these sorption sites. The water molecules penetrated the internal structure of rice flour consisting of crystalline and amorphous parts, and were sorbed or trapped in the internal sorption sites present in the structure. The crystal structure partially collapsed owing to the mechanical shock of milling, and the sorption sites in the crystal structure were damaged. It is expected that the effect of the mechanical shock on the crystalline structure was comparatively more severe than that on the amorphous structure. Consequently, the behavior of $q_{\mathrm{m}}$, as shown in Fig. 4, primarily reflected the decrease of sorption sites in the crystal structure.

The parameter $c$ of RFa-RFd was determined as 47.3 $\pm 12.7,44.5 \pm 0.29,47.6 \pm 7.8$, and $31.5 \pm 7.7$, respectively.


Fig. 4. Relationships between GAB parameters of each sample and DI. 


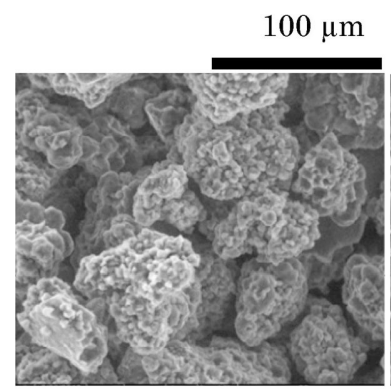

Humidity $=60 \%$

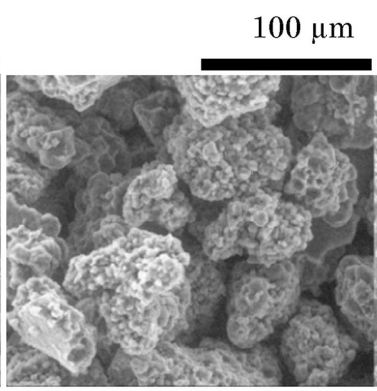

Humidity $=80 \%$
$100 \mu \mathrm{m}$

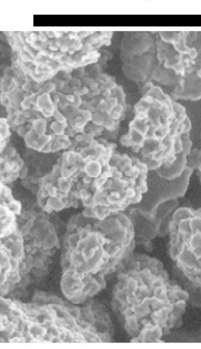

Humidity $=95 \%$

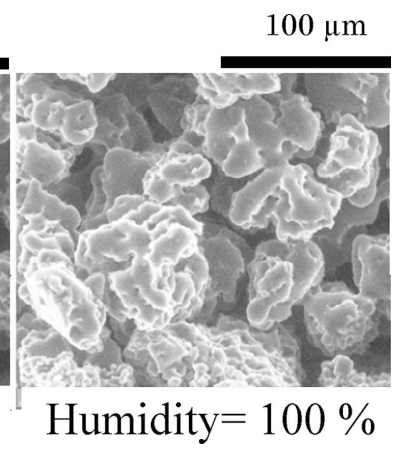

Fig. 5. SEM images of starch particles with humidity of $60-100 \%$.

No significant correlation was observed between the parameter $c$ and DI. Especially, the interaction between the water molecules and sorption sites did not depend on the structure of starch in rice flours. The parameter $K$ of $\mathrm{RFa}-$ $\mathrm{RFd}$ was determined as $0.78 \pm 0.01,0.80 \pm 0.01,0.82$ \pm 0.01 , and $0.79 \pm 0.01$, respectively. The parameter $K$ moved farther with regard to the value required for pure water $(K=1)$ as DI decreased. In addition, the parameter $K$ increased monotonically, corresponding to the degree of DI $\left(R^{2}=0.923\right)$.

Generally, the water molecules exist as strongly bound water at the sorption sites, weakly bound water in the structure, and free water, according to the degree of interaction. ${ }^{36)}$ In the case of rice flour, if certain water molecules penetrate the internal structure, the strongly bound water at the sorption sites, the weakly bound water with long-range interaction, and the nonspecific entrapped water exist in the structure. In the case of RFa-RFd around the $a_{\mathrm{w}}$ $>0.4$ region, the weakly bound water was more abundant than the strongly bound water. In the case of RFe, the nonspecific entrapped water might be predominant because the sorption site collapsed owing to the mechanical shock of milling. Overall, the chemical interaction between water molecule and sorption site was comparatively weak, corresponding to the disorder of the structure. Therefore, the decrease in sorption capacity of RFe in the $0.3-0.8 a_{\mathrm{w}}$ range might occur owing to collapse of sorption sites in the structure. As shown in Fig. 3, the amount of sorption water of RFe in the high $a_{\mathrm{w}}$ region $\left(a_{\mathrm{w}}>0.9\right)$ was higher than that of $\mathrm{RFa}$. Thus, water penetration into the internal structure of the crystalline sample was saturated at the high $a_{\mathrm{w}}$ region. The redundant water, consequently, might affect the internal structure.

To investigate experimentally the contribution of the redundant water on the structural change, rice starch particles with crystalline structures were obtained using the scanning electron microscope (Quanta 200, FEI. Co., Japan Ltd.) under 60-100\% humidity. As shown in Fig. 5, one can observe the structural change in the rice starch particles owing to the increase of humidity. Therefore, it is confirmed that the parameter $K$ is the effective tool to evaluate the solid state of rice flour, especially, the high crystalline samples.

\section{CONCLUSION}

This study was conducted to evaluate the change in the powder properties of rice flour induced by different milling methods. Rice flour samples were prepared by subjecting them to gradual mechanical shocks and the powder properties of each sample were investigated based on starch damage, which may directly reflect the extent of mechanical shock caused by milling.

None of the particle sizes of the samples correlated with starch damage. However, it was confirmed that wet milling could lead to particle homogeneity. Relationship between DI and starch damage was observed. This result suggests that the crystal state of starch in rice flour could be controlled by the mechanical shock from the milling process.

The moisture sorption isotherm agreed with the GAB equation. Additionally, the parameters $q_{\mathrm{m}}$ and $K$ correlated with DI. The sorption sites decreased because of mechanical shock, and parameter $K$ reflected a change in particle structure. These results successfully demonstrated that rice flour with arbitrary sorption properties could be produced by controlling the mechanical shock during the milling process.

\section{ACKNOWLEDGMENTS}

The rice flours used in this study were provided by Hatsuratsu Inc. This study was financially supported by the Matching Planner Program of the Japan Science and Technology Agency and the Iijima Memorial Foundation for the Promotion of Food Science and Technology.

\section{REFERENCES}

1) A. Buléon, P. Colonna, V. Planchot, and S. Ball: Starch granules: structure and biosynthesis. Int. J. Biol. Macromol., 23, 85-112 (1998).

2) R. Parker and S.G. Ring: Aspects of the physical chemistry of starch. J. Cereal Sci., 34, 1-17 (2001).

3) R.F. Tester, J. Karkalas, and X. Qi: Starch-composition, fine structure and architecture. J. Cereal Sci., 39, 151-165 (2004).

4) J.L. Jane: Structure of starch granules. J. Appl. Glycosci., 54, 31-36 (2007).

5) J.L. Jane: Current understanding on starch granule structures, J. Appl. Glycosci., 53, 205-213 (2006).

6) D. Le Corre, J. Bras, and A. Dufresne: Starch Nanoparticles: A review. Biomacromolecules, 11, 1139-1153 (2010). 
7) A. Lopez-Rubio, B.M. Flanagna, E.P. Gilbert, and M.J. Gidley: A novel approach for calculating starch crystallinity and its correlation with double helix content: A combined XRD and NMR study. Biopolymers, 89, 761-768 (2008).

8) K.D. Nishita and M.M. Bean: Grinding methods: their impact on rice flour properties. Cereal Chem., 59, 46-49 (1982).

9) M. Arisaka, K. Nakamura, and Y. Yoshii: Properites of rice flour prepared by different milling methods. J. Jpn. Soc. Starch Sci., 39, 155-163 (1992). (in Japanese)

10) P.Y. Chiang and A.I. Yeh: Effect of soaking on wet-milling of rice. J. Cereal Sci., 35, 85-94 (2002).

11) P. Ngamnikom and S. Songsermpong: The effects of freeze, dry, and wet grinding processes on rice flour properties and their energy consumption. J. Food Eng., 104, 632-638 (2011).

12) S. Tamaki, M. Hisamatsu, K. Teranishi, and T. Yamada: Structural Change of Wheat Starch Granule by Ball-mill Treatment, J. Appl. Glycosci., 44, 505-513 (1997).

13) R. Asmeda, A. Noorlaila, and M.H. Norziah: Effects of different grinding methods on chemical and functional properties of MR211 rice flour. Int. J. Food Eng., 1, 111-114 (2015).

14) B. Santoso, K. Sakakura, H. Naito, M. Ohmi, Y. Nishimura, T. Uchiyama, A Itaya, M. Hisamatsu, H. Ehara, and T. Mishima: Effects of micro powder milling on physicochemical properties of sago starch. J. Appl. Glycosci., 62, 73-80 (2015).

15) Z. Huang, J. Lu, X. Li, and Z. Tong: Effect of mechanical activation on physicochemical properties and structure of cassava starch. Carbohydr. Polym., 68, 128-135 (2007).

16) J. Lellievre: Starch damage. Starch, 26, 85-88 (1974).

17) P.Y. Lin and Z. Czuchajowska: Starch damage in soft wheats of the pacific northwest. Carbohydrates, 73, 551555 (1996).

18) D.W. Hatcher, M.J. Anderson, R.G. Desjadins, N.M. Edwards, and J.E. Dexter: Effect of flour particle size and starch damage on processing and quality of white salted noodles. Cereal Chem., 79, 64-79 (2002).

19) W.R. Morrison, R.F. Tester, and M.J. Gidley: Properties of damaged starch granules II. Crystallinity, molecular order and gelatinisation of ball-milled starches. J. Cereal Sci., 19, 209-217 (1994).

20) R.F. Tester, W.R. Morrison, M.J. Gidley, M. Kirkland, and J. Karkalas: Properties of damaged starch granules III. Microscopy and particle size analysis of undamaged granules and remnants. J. Cereal Sci., 20, 59-67 (1994).

21) W.R. Morrison, R.F. Tester, and M.J. Gidley: Properties of damaged starch granules IV. Composition of ball-milled wheat starches and of fractions obtained on hydration. $J$. Cereal Sci., 20, 69-71 (1994).
22) R.S. Kandan, R.J. Bryant, and J.A. Miller: Effects of milling on functional properties of rice flour. J. Food Sci., 73, 151-154 (2008).

23) Y. Sato, Y. Wada, and A. Higo: Analysis of water layers and the extent of gelatinization for commercial starch products. J. Food Eng., 100, 201-207 (2010).

24) S. Murakami, M. Kuramochi, T. Koda, T. Nishio, and A. Nishioka: Relationship between rice flour particle sizes and expansion ratio of pure rice bread. J. Appl. Glycosci., 63, 19-22 (2016).

25) N. Shoji, Y. Hanyu, S. Mohri, S. Hatanaka, M. Ikeda, C. Togashi, and T. Fujii: Evaluation of powder and hydration properties of rice flour milled by different techniques. Nippon Shokuhin Kagaku Kogaku Kaishi, 59, 192-198 (2012). (in Japanese)

26) T. Fujii and N. Shoji: The fine structure of rice-starch. Bull. Appl. Glycosci., 2, 92-96 (2012). (in Japanese)

27) T.B.T. Tran, K.J. Shelat, D. Tang, E. Li, R.G. Gilbert, and J. Hasjim: Milling of rice grains. The degradation on three structural levels of starch in rice flour can be independently controlled during grinding. J. Agric. Food Chem., 59, 3964-3973 (2011).

28) M. Anzai, T. Hagiwara, M. Watanabe, J. Komiyama, and T. Suzuki: Relationship between enthalpy relaxation and water sorption of ball-milled potato starch. J. Food Eng., 104, 43-48 (2011).

29) T. Okunishi: Future on rice flour bread, J. Cookery Sci. Jpn., 48, 385-391 (2015). (in Japanese)

30) Y.J. Kim, T. Suzuki, T. Hagiwara, I. Yamaji, and R. Takai: Enthalpy relaxation and glass to rubber of amorphous potato starch formed by ball-milling. Carbohydr. Polym., 46, $1-6(2001)$.

31) K. Katsuno, A. Nishioka, T. Koda, K. Miyata, and G. Murasawa: Novel method for producing amorphous rice flours by milling without adding water. Starch/Stärke, 62, 475479 (2010).

32) S. Nara: On the water sorption in starch granules. J. Jpn. Soc. Starch Sci., 28, 24-32 (1981). (in Japanese)

33) S. Nara and T. Komiya: Studied on the relationship between water-saturated state and crystallinity by the diffraction method for moistened potato starch. Starch/Stärke, 35, 407-410 (1983).

34) M. Anzai, T. Fukami, M. Watanabe, and T. Suzuki: Reduction of moisture absorption of amorphous rice flour formed by ball milling. Jpn. J. Food Eng., 15, 173-179 (2014). (in Japanese)

35) S.S. Sabani, S. Kasapis, M.S. Rahman, A. Al-Jabri, and N. Al-Habsi: Sorption isotherms and the state diagram for evaluating stability criteria of abalone. Food Res. Int., 37, 915-924 (2004).

36) O.R. Fennema ed.: Principle of Food Science Part 1., Food Chemistry, Marcel Dekker, New York, pp.28 (1975). 